\title{
Influence of polymeric matrix on the physical and chemical properties of experimental composites
}

Flávia GONÇALVES(a)

Leticia Cristina Cidreira BOARO(b)

Caroline Lumi MIYAZAKI(c)

Yoshio KAWANO(d)

Roberto Ruggiero BRAGA ${ }^{(e)}$

(a) Universidade Ibirapuera - UNIB, Faculdade de Odontologia, São Paulo, SP, Brazil.

(b) Universidade de Santo Amaro - UNISA, Faculdade de Odontologia, São Paulo, SP, Brazil.

(c) Universidade de São Paulo - USP, Faculdade de Odontologia, São Paulo, SP, Brazil.

(d) Universidade de São Paulo - USP, Instituto de Química, SP, Brazil.

(e) Universidade de São Paulo - USP, Faculdade de Odontologia, São Paulo, SP, Brazil.

Declaration of Interests: The authors certify that they have no commercial or associative interest that represents a conflict of interest in connection with the manuscript.

Corresponding Author:

Flávia Gonçalves

E-mail: flaviapec@ig.com.br

DOI: 10.1590/1807-3107BOR-2015.vol29.0128

Submitted: Oct 14, 2014

Accepted for publication: Jun 09, 2015

Last revision: Aug 21, 2015

\begin{abstract}
Nowadays, the main reasons for replacement of resin-based composite restorations are fracture or problems with the integrity of their interface, such as marginal staining, microleakage, or secondary caries. The aim of the present study was to evaluate the influence of the organic matrix on polymerization stress (PS), degree of conversion (DC), elastic modulus (E), flexural strength (FS), Knoop hardness $(\mathrm{KHN})$, sorption (SP), and solubility (SL). In order to obtain a material which combines better mechanical properties with lower PS, seven experimental composites were prepared using BisGMA to TEGDMA molar ratios of 2:8, 3:7, 4:6, 5:5, 6:4, 7:3 and 8:2 and 40\% of silica. PS was obtained in a universal testing machine, using acrylic as bonding substrate. DC was determined using Fourier Transform Raman spectroscopy. E and FS were obtained by the three-point bending test. $\mathrm{KHN}$ was measured by a microindentation test using a load of $25 \mathrm{~g}$ for 30 s. SP and SL were assessed according to ISO 4049. The data were submitted to one-way ANOVA. The increase in BisGMA concentration resulted in the decrease of PS, DC, E, FS and KHN. However, it did not change the SP and SL values. FS, E and KHN showed a strong and direct relationship with the DC of the materials. The composite material with a BisGMA to TEGDMA molar ratio of 1:1 was the one with better mechanical properties and lower PS.
\end{abstract}

Keywords: Composite Resins; Materials Testing; Dental Stress Analysis.

\section{Introduction}

One of the main challenges of dentistry is to combine low polymerization stress and better mechanical properties in the same composite restorative material, since clinical studies point to loss of marginal integrity and fractures as the main reasons for failure in resin-based composite restorations. ${ }^{1,2,3}$

Polymerization stress originates from the combination of several factors, such as volumetric shrinkage, elastic modulus, viscosity, reaction kinetics, and degree of conversion. $4,5,6,7,8,9$ And all these factors are influenced by monomer composition. ${ }^{10,11,12}$ In fact, in BisGMA-TEGDMA mixtures, the base monomer concentration increases the viscosity, resulting in a maximum polymerization rate in the early stages of polymerization, leading to a lower final conversion, volumetric shrinkage, and polymerization stress. ${ }^{8,12,13,14}$

Notwithstanding, although some authors have observed a strong relationship between mechanical properties and the degree of conversion 
of materials, $8,15,16,17$ such relationship is not always verified, since features such as material structure, crosslink density and secondary bonds can affect the resistance of the material to mechanical stress. ${ }^{18,19,20,21,22}$ Therefore, the simultaneous effect of conversion and structure on mechanical properties should be considered. ${ }^{18,19,23}$ The higher concentration of BisGMA when blended with UDMA and TEGDMA reduced the degree of conversion of the composite, but the flexural strength, elastic modulus, fracture toughness, and hardness of some of the materials tested were maintained. ${ }^{20}$ The high concentration of BisGMA decreases strength, on the one hand, by reducing conversion and crosslink density, and increases it, on the other, because it contains low-mobility rigid molecules, thereby forming hydrogen bonds between the polymer chains. . $^{18,19,23}$

Therefore, an ideal restorative material should be one that combines low polymerization stress and better mechanical properties, taking into account polymeric matrix composition, structure, and degree of conversion. Some studies have evaluated the influence of the monomer ratio on polymerization stress $^{6,12}$ while others have evaluated its influence on mechanical properties. ${ }^{16,18,21}$ There is a paucity of studies focusing simultaneously on polymerization stress and physicomechanical properties and aimed at obtaining an ideal monomer ratio.

The aim of this study was to evaluate the influence of polymeric a BisGMA-TEGDMA matrix on polymerization stress and on the physical and chemical properties (flexural strength, elastic modulus, hardness, sorption, and solubility) of experimental composites, in an attempt to determine the relationship between low polymerization stress and better mechanical properties. The null hypothesis shows that polymerization stress and mechanical properties do not correlate with the degree of conversion.

\section{Methodology}

\section{Preparation of composites}

Seven experimental composites were prepared containing 40 wt $\%$ OX-50 silica (Degussa, Americana, Brazil), previously silanized by the manufacturer and averaging $0.04 \mu \mathrm{m}$ in size; BisGMA (2,2bis[4-(2-hydroxy-3-methacryloxypropoxy)phenyl]propane) (ESSTECH Technology Inc., Essington, England), and TEGDMA (triethyleneglycol dimethacrylate) (ESSTECH Technology Inc., Essington, England) at the ratios of 2:8, 3:7, 4:6, 5:5, 6:4, 7:3 and 8:2. The photoinitiator system was composed of $2 \mathrm{~mol} \%$ of 2-(dimethylamino) ethyl methacrylate (Sigma-Aldrich Inc., St. Louis, USA) and $2 \mathrm{~mol} \%$ of camphorquinone (Sigma-Aldrich Inc., St. Louis, USA). The composites were prepared in a dark room. Resin-based composites were kept under refrigeration until two hours before use and then used at room temperature.

\section{Polymerization stress}

The polymerization stress test $(n=5)$ used poly-(methyl methacrylate) rods as bonding substrate for the composite (radius of $3 \mathrm{~mm}$ and length of 13 or $28 \mathrm{~mm}$ ). The rods were attached to a universal testing machine (Instron 5565, Canton, USA). The composite was inserted ( $\mathrm{h}=1 \mathrm{~mm}$ ) and photoactivated with a quartz-tungsten-halogen light curing unit (VIP Junior, Bisco, Schaumburg, USA), resulting in a radiant exposure of $18 \mathrm{~J} / \mathrm{cm}^{2}$. An extensometer (model 2630-101, Instron) was used to keep the specimen height constant, with $0.1 \mu \mathrm{m}$ of accuracy. The contraction force rate was monitored for 15 min and maximum nominal stress was obtained by dividing the maximum contraction force by the rod area.

\section{Degree of conversion}

Degree of conversion, assessed by Fourier transform Raman spectrometry (RFS 100/S, Bruker Optics Inc., Billerica, USA), was performed in cylindrical specimens $15 \mathrm{~min}$ after polymerization (radius of $2.5 \mathrm{~mm}$; height of $1 \mathrm{~mm} ; \mathrm{n}=3$ ). The specimens were polymerized with a radiant exposure of $18 \mathrm{~J} / \mathrm{cm}^{2}$ (VIP Junior, BISCO, Schaumburg, USA). In the polymerized specimens, the spectra were collected from the non-irradiated bottom surface. The spectra were obtained by the co-addition of 64 scans between 2,000 and $100 \mathrm{~cm}^{-1}$, at a resolution of 4 $\mathrm{cm}^{-1}$ and power of $100 \mathrm{~mW}$. The same procedure was carried out for the uncured materials. The ratio of the absorbance peaks corresponding to the aliphatic $\left(1,640 \mathrm{~cm}^{-1}\right)$ and aromatic $\left(1,610 \mathrm{~cm}^{-1}\right)$ carbon double 
bonds for the cured and uncured composite was used to calculate conversion.

\section{Flexural strength and elastic modulus}

Bar-shaped specimens were fabricated using a stainless steel split mold $\left(10 \times 2 \times 1 \mathrm{~mm}^{3}, \mathrm{n}=10\right)$. Photoactivation followed the same parameters used in the previous tests $\left(18 \mathrm{~J} / \mathrm{cm}^{2}\right)$. The specimens were subjected to the three-point bending test $15 \mathrm{~min}$ after photoactivation in a universal testing machine (Instron 5565, Canton, USA) with an $8 \mathrm{~mm}$ span between supports. The load at fracture and the specimen sizes (determined individually with a digital caliper) were used to calculate flexural strength.

The flexural modulus was determined using data from the initial linear portion of the load-displacement curve.

\section{Knoop hardness (KHN)}

Five specimens were prepared for each group, using a stainless steel split mold $\left(10 \times 2 \times 1 \mathrm{~mm}^{3}\right)$ and a Mylar strip. The photoactivation procedure was the same one used in the tests described before. The Knoop hardness test was carried out $15 \mathrm{~min}$ after photoactivation using an HMV-2 microindenter (Shimadzu, Tokyo, Japan), with a load of $25 \mathrm{~g}$ and a dwell-time of $30 \mathrm{~s}$. Five measurements were taken from each specimen, on the non-irradiated surface.

\section{Sorption and solubility}

Cylindrical specimens $(\mathrm{r}=7.5 \mathrm{~mm}$ and $\mathrm{h}=1$ $\mathrm{mm})$ were prepared using a steel matrix $(n=5)$. The specimens were photoactivated on both sides with a radiant exposure of $18 \mathrm{~J} / \mathrm{cm}^{2}\left(900 \mathrm{~mW} / \mathrm{cm}^{2}\right.$ for 20 seconds), using Flash Lite 1401 (Discus Dental, Culver City, USA), a high-powered LED curing unit. The specimens were stored in a vacuum desiccator at $37^{\circ} \mathrm{C}$ for 28 days until they reached a steady state. The specimens were weighed in an analytical balance (Ohaus-Adventure, AR214N, Shanghai, China) to determine $\mathrm{m}_{1}$ and immersed in distilled water, which was changed weekly. The specimens were stored in water at $37^{\circ} \mathrm{C}$ for 28 days. The specimens were dried with absorbent paper and weighed to determine $\mathrm{m}_{2}$. They were stored in a vacuum desiccator for 90 days to obtain $\mathrm{m}_{3}$. Sorption (SW) was calculated by dividing the difference between $\mathrm{m}_{2}$ and $\mathrm{m}_{1}$ by the specimen volume, whereas solubility (SL) was calculated by dividing the difference between $\mathrm{m}_{1}$ and $\mathrm{m}_{3}$ by the specimen volume.

\section{Statistical analysis}

After being tested for homocedasticity and normality, using Levene's and Anderson-Darling tests, respectively, the data were submitted to one-way ANOVA and Tukey's test, with a global significance level of $95 \%(a=0.05)$ for each test. Regression analyses were performed for all the studied properties, using the degree of conversion as the independent variable. The data were analyzed using the Minitab 17 software (Minitab Inc., State College, USA).

\section{Results}

Table 1 shows the mean \pm standard deviation of the physical and mechanical properties: polymerization stress, elastic modulus, flexural strength, Knoop hardness, sorption, solubility, and degree of conversion. The increase of BisGMA content is directly associated with the decrease of these mechanical properties and of polymerization stress. The degree of conversion also shows an inverse correlation with BisGMA concentration. However, sorption and solubility did not show statistical difference in the BisGMA to TEGDMA ratio. The power of the sorption and solubility tests yielded high values ( $92 \%$ and $74 \%$ respectively).

The correlation coefficients of the evaluated properties, as a function of the degree of conversion, are shown in Figure 1. Elastic modulus, flexural strength, Knoop hardness, and polymerization stress showed a strong, direct and linear relationship with degree of conversion.

\section{Discussion}

The null hypothesis that polymerization stress and physicochemical properties do not correlate with the degree of conversion can be partially rejected, since some properties, such as elastic modulus, flexural strength, Knoop hardness, and polymerization stress, are strongly related to the degree of conversion, while other properties, such as sorption and solubility, are not. 
Table 1. Means \pm standard deviation of polymerization stress (MPa), elastic modulus (GPa), flexural strength (MPa), Knoop hardness, sorption $\left(\mu \mathrm{g} / \mathrm{mm}^{3}\right)$, solubility $\left(\mu \mathrm{g} / \mathrm{mm}^{3}\right)$ and degree of conversion (\%) of experimental composites containing BisGMA and TEGDMA at different ratios and $40 \mathrm{wt} \%$ of colloidal silica.

\begin{tabular}{|c|c|c|c|c|c|c|c|}
\hline $\begin{array}{l}\text { BisGMA: } \\
\text { TEGDMA }\end{array}$ & $\begin{array}{l}\text { Polymerization } \\
\text { stress (MPa) }\end{array}$ & $\begin{array}{l}\text { Elastic Modulus } \\
\text { (GPa) }\end{array}$ & $\begin{array}{l}\text { Flexural Strength } \\
\qquad(\mathrm{MPa})\end{array}$ & Knoop Hardness & $\begin{array}{l}\text { Sorption } \\
\mu \mathrm{g} / \mathrm{mm}^{3}\end{array}$ & $\begin{array}{l}\text { Solubility } \\
\mu \mathrm{g} / \mathrm{mm}^{3}\end{array}$ & $\begin{array}{c}\text { Degree of } \\
\text { conversion (\%) }\end{array}$ \\
\hline $2: 8$ & $8.4 \pm 0.8^{a}$ & $1.9 \pm 0.2^{a}$ & $73.4 \pm 6.3^{\circ}$ & $11.6 \pm 0.5^{a b}$ & $37.7 \pm 4.0^{\circ}$ & $13.7 \pm 4.2^{a}$ & $63.2 \pm 2.8^{a b}$ \\
\hline $3: 7$ & $7.2 \pm 0.7^{b}$ & $1.8 \pm 0.1^{a b}$ & $69.1 \pm 10.3^{a}$ & $12.6 \pm 1.1^{a}$ & $33.4 \pm 7.0^{\circ}$ & $13.2 \pm 4.1^{a}$ & $66.6 \pm 2.7 a$ \\
\hline $4: 6$ & $7.0 \pm 0.7^{b}$ & $1.8 \pm 0.2^{a b}$ & $67.3 \pm 10.7^{a b}$ & $10.6 \pm 0.9^{b}$ & $30.2 \pm 4.9^{a}$ & $15.9 \pm 4.0^{a}$ & $64.1 \pm 0.6 \mathrm{ab}$ \\
\hline $5: 5$ & $5.6 \pm 0.4^{c}$ & $1.6 \pm 0.2 b c$ & $63.7 \pm 6.9 \mathrm{ab}$ & $10.5 \pm 0.5^{b}$ & $31.9 \pm 5.9^{a}$ & $15.6 \pm 4.2^{a}$ & $60.5 \pm 1.6^{b}$ \\
\hline $6: 4$ & $4.6 \pm 0.2 \mathrm{~cd}$ & $1.4 \pm 0.2^{c}$ & $56.9 \pm 8.2 b c$ & $8.4 \pm 0.9 c$ & $33.6 \pm 3.1^{a}$ & $21.2 \pm 8.2^{a}$ & $53.4 \pm 2.3^{c}$ \\
\hline $7: 3$ & $4.3 \pm 0.5 \mathrm{de}$ & $1.1 \pm 0.2^{d}$ & $51.4 \pm 6.8^{c}$ & $5.8 \pm 0.3^{d}$ & $25.8 \pm 7.4^{a}$ & $25.4 \pm 6.4^{a}$ & $50.0 \pm 1.2^{c d}$ \\
\hline $8: 2$ & $3.4 \pm 0.2 \mathrm{e}$ & $0.7 \pm 0.1 \mathrm{e}$ & $40.3 \pm 6.1^{d}$ & $3.9 \pm 0.3^{e}$ & $28.3 \pm 6.4^{\circ}$ & $24.1 \pm 5.7^{a}$ & $44.7 \pm 2.2^{d}$ \\
\hline
\end{tabular}

Means followed by the same letter in the same column indicate lack of statistically significant difference.

A
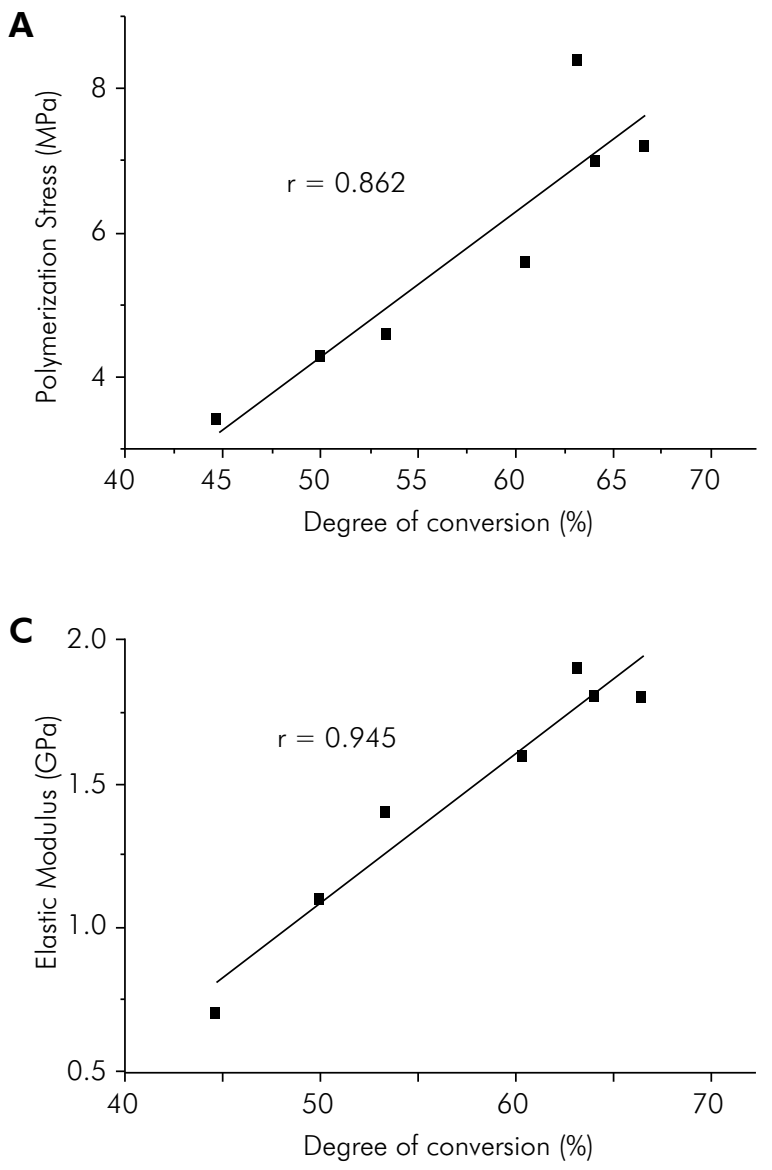

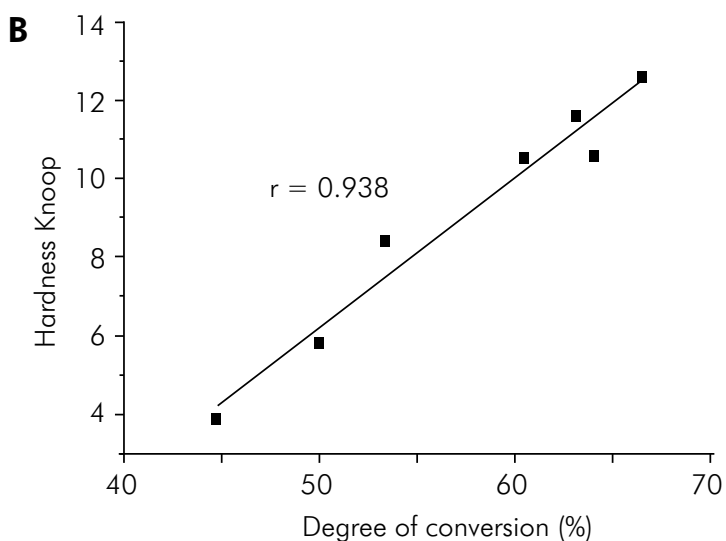

D

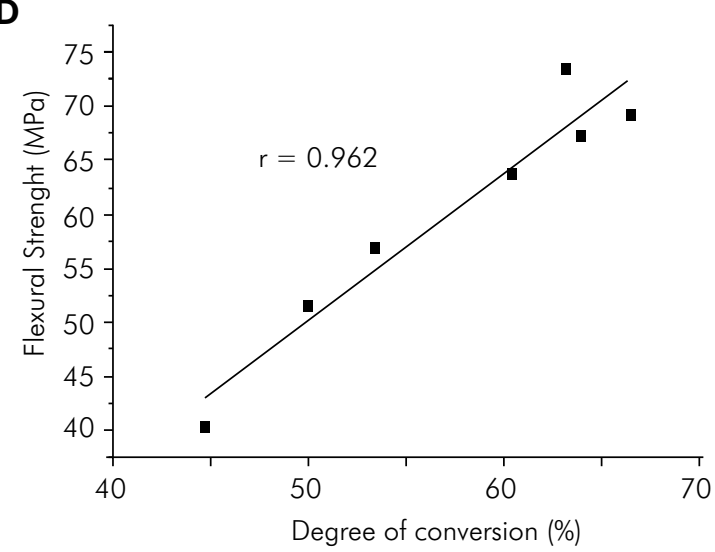

Figure 1. Analysis of the linear correlation between polymerization stress (A), Knoop hardness (B), elastic modulus (C), flexural strength (D), and degree of conversion.

The polymerization stress test was performed in a high compliance system. This high compliance system allows for the analysis of materials with high polymerization stress values (e.g., $8 \mathrm{Mpa})$. This analysis could not be done in a low compliance system, where for example, glass, because of its low strength, is used instead of acrylic rods. It is known that in the high compliance system, materials 
with a higher elastic modulus are able to strain the system and relieve part of the stress. ${ }^{24}$ However, in the studied materials it could not change the ranking of the materials, since those with a higher elastic modulus were also the ones with higher polymerization stress. This helped qualify the test system used.

The increase in polymerization stress obtained by reducing base monomer concentration was observed in several other studies. ${ }^{6,12,13}$ In fact, the decrease of base monomer in BisGMA-TEGDMA blends is associated with an increase in shrinkage and, therefore, in the degree of conversion. ${ }^{10,18}$ This, associated with the increase of elastic modulus, ${ }^{8,25}$ would lead to the increase in polymerization stress values. ${ }^{12}$

The increase in the degree of conversion, as a result of the increase in TEGDMA concentration when using BisGMA as co-monomer, occurs because the diluent monomer decreases the viscosity of the mixture and increases the mobility of the reaction medium. This allows delaying the self-acceleration and self-deceleration stages, ensuring a higher final conversion of the material. ${ }^{14,26}$

Flexural strength, flexural modulus, and Knoop hardness showed a direct relationship with TEGDMA concentration in the mixture, due to two main factors. The first factor is concerned with the strong direct relationship of these mechanical properties with the degree of conversion of the materials, as shown by the correlation coefficients presented in Figure 1 ( $\mathrm{r}$ higher than 0.862). Such correlations differ from that study which also assessed BisGMA-TEGDMA blends at different molar ratios, revealing that the increase in BisGMA concentration led to a significant reduction in density conversion, without affecting flexural strength. ${ }^{18}$ One possible reason for this discrepancy between the studies is that the present study used a filler concentration of $40 \mathrm{wt} \%$, compared to $75 \mathrm{wt} \%$ in the afore-mentioned study. The lower filler volume may be better at showing the effect of the organic matrix on the evaluated properties. However, these results are consistent with those of the study that evaluated different BisEMA and TEGDMA unfilled resin concentrations, which were strongly correlated with increased elastic modulus and hardness, when the concentration of TEGDMA monomers and the degree of conversion were increased. ${ }^{17}$ The second factor, which associates the increase in TEGDMA concentration with the improvement of mechanical properties, is related to material structure. The increase of TEGDMA, to some extent, can be associated with a higher packing of chains and a reduction in the free volume of the material, ${ }^{21,27}$ which also yield better mechanical properties.

Although the materials with a higher TEGDMA concentration had a higher degree of conversion, sorption did not decrease with the increase in the concentration of this monomer. This was probably caused by two opposite factors: first, the increase in the degree of conversion results in a highly cross-linked network. This high density can cause water uptake to decrease. On the other hand, the higher amount of TEGDMA, a more hydrophilic monomer compared to BisGMA, increases water sorption. ${ }^{27}$

There was no statistical difference in the solubility of the materials. In fact, several studies showed that a higher degree of conversion and a highly cross-linked polymer network lower the concentration of residual monomers, thereby reducing leaching. ${ }^{6,27}$ On the other hand, the molecular weight of TEGDMA is almost half that of BisGMA, and thus the solubility of the former is facilitated even in densely cross-linked networks.

Despite the limitations of this study, regarding the organic matrix, the balance between low polymerization stress and better mechanical properties can be obtained with a BisGMA to TEGDMA ratio of 1:1, which is in agreement with the findings reported by other authors. ${ }^{18,28}$ The use of an equimolar monomer concentration allowed decreasing polymerization stress by approximately $33 \%$ and mechanical properties by $15 \%$. Conversely, composite materials with higher concentrations of TEGDMA revealed negligible decreases in polymerization stress, which are very similar to those decreases observed in mechanical properties. While there is a greater reduction in polymerization stress when lower concentrations of TEGDMA are used, there always occurs a significant decrease in at least one of mechanical properties. For example, BisGMA concentrations of $80 \mathrm{~mol} \%$ reduce 
polymerization stress by $60 \%$, hardness and elastic modulus; however, flexural strength is reduced by $45 \%$, which may be due to the morphological differences in the polymer network.

A low inorganic content was used in the present study to demonstrate the influence of the organic matrix on mechanical properties and to generate materials with adequate handling consistency. Previous studies, ${ }^{12,29}$ conducted between 2011 and 2010, show that inorganic content can affect the properties of composite materials. ${ }^{12,29}$ Therefore, high concentrations of filler particles were avoided in this study not to bias the results and to disguise the real effect of the organic matrix.

\section{References}

1. Brunthaler A, Konig F, Lucas T, Sperr W, Schedle A. Longevity of direct resin composite restorations in posterior teeth. Clin Oral Investig. 2003;7(2):63-70. doi:10.1007/s00784-003-0206-7

2. Deligeorgi V, Mjör IA, Wilson NH. An overview of reasons for the placement and replacement of restorations. Prim Dent Care. 2001;8(1):5-11. doi:10.1308/135576101771799335

3. Forss H, Widstrom E. Reasons for restorative therapy and the longevity of restorations in adults. Acta Odontol Scand. 2004;62(2):82-6. doi:10.1080/00016350310008733

4. Boaro LC, Goncalves F, Guimaraes TC, Ferracane JL, Versluis A, Braga RR. Polymerization stress, shrinkage and elastic modulus of current low-shrinkage restorative composites. Dent Mater. 2010;26(12):1144-50. doi:10.1016/j.dental.2010.08.003

5. Charton C, Colon P, Pla F. Shrinkage stress in light-cured composite resins: influence of material and photoactivation mode. Dent Mater. 2007;23(8):911-20. doi:10.1016/j.dental.2006.06.034

6. Gonçalves F, Pfeifer CS, Ferracane JL, Braga RR. Contraction stress determinants in dimethacrylate composites. J Dent Res. 2008;87(4):367-71. doi:10.1177/154405910808700404

7. Kleverlaan CJ, Feilzer AJ. Polymerization shrinkage and contraction stress of dental resin composites. Dent Mater. 2005;21(12):1150-57. doi:10.1016/j.dental.2005.02.004

8. Abu-elenain DA, Lewis SH, Stansbury JW. Property evolution during vitrification of dimethacrylate photopolymer networks. Dent Mater. 2013;29(11):1173-81. doi:10.1016/j.dental.2013.09.002

9. Charton C, Falk V, Marchal P, Pla F, Colon P. Influence of T(g), viscosity and chemical structure of monomers on shrinkage stress in light-cured dimethacrylate-based dental resins. Dent Mater. 2007;23(11):1447-59. doi:10.1016/j.dental.2007.05.017

\section{Conclusion}

The analysis of the polymeric matrix revealed that mechanical properties are strong and directly related to the degree of conversion of the materials, as also occurs with polymerization stress. The balance between mechanical properties and polymerization stress was obtained at the BisGMA to TEGDMA molar ratio of 1:1. Therefore, the development and improvement of restorative materials should take into account this ratio so that resin-based composites yield the best possible performance.

\section{Acknowledgments}

The authors would like to thank ESSTECH for donating the monomers used in this study.

10. Dewaele M, Truffier-Boutry D, Devaux J, Leloup G. Volume contraction in photocured dental resins: the shrinkage-conversion relationship revisited. Dent Mater. 2006;22(4):359-65. doi:10.1016/j.dental.2005.03.014

11. Gajewski VE, Pfeifer CS, Froes-Salgado NR, Boaro LC, Braga RR. Monomers used in resin composites: degree of conversion, mechanical properties and water sorption/solubility. Braz Dent J. 2012;23(5):508-14. doi:10.1590/S0103-64402012000500007

12. Gonçalves F, Azevedo CL, Ferracane JL, Braga RR. BisGMA/TEGDMA ratio and filler content effects on shrinkage stress. Dent Mater. 2011;27(6):520-6. doi:10.1016/j.dental.2011.01.007

13. Feilzer AJ, Dauvillier BS. Effect of TEGDMA/BisGMA ratio on stress development and viscoelastic properties of experimental two-paste composites. J Dent Res. 2003;82(10):824-8. doi:10.1177/154405910308201012

14. Lovell LG, Stansbury JW, Syrpes DC, Bowman CN. Effects of composition and reactivity on the reaction kinetics of dimethacrylate/dimethacrylate copolymerizations. Macromolecules. 1999;32(12):3913-21. doi:10.1021/ma990258d

15. Asmussen E. Restorative resins: hardness and strength vs. quantity of remaining double bonds. Scand J Dent Res. 1982;90(6):484-489.

16. Ferracane JL, Greener EH. The effect of resin formulation on the degree of conversion and mechanical properties of dental restorative resins. J Biomed Mater Res. 1986;20(1):121-31. doi:10.1002/jbm.820200111

17. Lin-Gibson S, Landis FA, Drzal PL. Combinatorial investigation of the structure-properties characterization of photopolymerized dimethacrylate networks. Biomaterials 2006;27(9):1711-17. doi:10.1016/j.biomaterials.2005.10.040 
18. Floyd CJ, Dickens SH. Network structure of Bis-GMA- and UDMA-based resin systems. Dent Mater. 2006;22(12):1143-9. doi:10.1016/j.dental.2005.10.009

19. Gonçalves F, Kawano Y, Pfeifer C, Stansbury JW, Braga RR. Influence of BisGMA, TEGDMA, and BisEMA contents on viscosity, conversion, and flexural strength of experimental resins and composites. Eur J Oral Sci. 2009;117(4):442-6. doi:10.1111/j.1600-0722.2009.00636.x

20. Musanje L, Ferracane JL. Effects of resin formulation and nanofiller surface treatment on the properties of experimental hybrid resin composite. Biomaterials. 2004;25(18):4065-71. doi:10.1016/j.biomaterials.2003.11.003

21. Pfeifer CS, Shelton ZR, Braga RR, Windmoller D, Machado JC, Stansbury JW. Characterization of dimethacrylate polymeric networks: a study of the crosslinked structure formed by monomers used in dental composites. Eur Polym J. 2011;47(2):162-70. doi:10.1016/j.eurpolymj.2010.11.007

22. Ye Q, Spencer P, Wang Y, Misra A. Relationship of solvent to the photopolymerization process, properties, and structure in model dentin adhesives. J Biomed Mater Res A. 2007;80(2):342-50. doi:10.1002/jbm.a.30890

23. Lemon MT, Jones MS, Stansbury JW. Hydrogen bonding interactions in methacrylate monomers and polymers. J Biomed Mater Res A. 2007;83(3):734-46. doi:10.1002/jbm.a.31448

24. Gonçalves F, Boaro LC, Ferracane JL, Braga RR. A comparative evaluation of polymerization stress data obtained with four different mechanical testing systems. Dent Mater. 2012;28(6):680-6. doi:10.1016/j.dental.2012.03.004

25. Condon JR, Ferracane JL. Assessing the effect of composite formulation on polymerization stress. J Am Dent Assoc. 2000;131(4):497-503. doi:10.14219/jada.archive.2000.0207

26. Dickens S, Stansbury J, Choi K, Floyd C. Photopolymerization kinetics of methacrylate dental resins. Macromolecules. 2003;36(16):6043-53. doi:10.1021/ma021675k

27. Sideridou I, Tserki V, Papanastasiou G. Study of water sorption, solubility and modulus of elasticity of light-cured dimethacrylate-based dental resins. Biomaterials. 2003;24(4):655-65. doi:10.1016/S0142-9612(02)00380-0

28. Asmussen E, Peutzfeldt A. Influence of UEDMA BisGMA and TEGDMA on selected mechanical properties of experimental resin composites. Dent Mater. 1998;14(1):51-6. doi:10.1016/S0109-5641(98)00009-8

29. Gonçalves F, Kawano Y, Braga RR. Contraction stress related to composite inorganic content. Dent Mater. 2010;26(7):704-9. doi:10.1016/j.dental.2010.03.015 